\title{
DECHLORINATION OF PLASTIC-RICH FRACTIONS REJECTED FROM WASTE ELECTRIC AND ELECTRONIC EQUIPMENT RECYCLING PLANTS BY MEANS OF STEPWISE PYROLYSIS FOR VALORIZATION
}

\author{
BORJA B. PEREZ-MARTINEZ, ALEXANDER LOPEZ-URIONABARRENECHEA, \\ ADRIANA SERRAS-MALILLOS, ESTHER ACHA, MIREN I. MARTÍNEZ-SANTOS, \\ AITZIBER IRIONDO \& BLANCA M. CABALLERO \\ Department of Chemical and Environmental Engineering, Faculty of Engineering of Bilbao, \\ University of the Basque Country (UPV/EHU), Spain
}

\begin{abstract}
Waste from Electric and Electronic Equipment (WEEE) is a rapid growing waste stream, with an 18 wt. \% increase from 2014 to 2019 . The great polymeric nature of this stream makes it prone to be used as feed in processes for the production of alternative fuels. However, the presence of halogens in the formula of the polymers lead to their release when combusted, and combined with the presence of organic compounds, to the production of dioxins and furans, strong pollutants for humans and the environment. In this work a rejected stream from a WEEE recycling plant was studied to determine the suitability of a pyrolysis process for the production of alternative liquid fuel. The initial analysis of the sample revealed an $80 \mathrm{wt}$. \% of volatile matter coming from the high polymeric nature, which was mostly composed of styrene and other thermoplastics, and 7,767 ppm of chlorine. Two main temperature driven degradation steps were found at $300^{\circ} \mathrm{C}$ and $420^{\circ} \mathrm{C}$. The pyrolysis temperature was set at $500^{\circ} \mathrm{C}$, under a heating rate of $15^{\circ} \mathrm{C} /$ minute with a 30 minute dwell time, and the system was purged with a nitrogen flow of $1 \mathrm{dm}^{3} / \mathrm{min}$. Under these parameters a $70 \mathrm{wt}$ \% liquid yield was achieved, with 5,375 ppm chlorine content. In order to lower the chlorine concentration in the resulting products, a dechlorination step was studied at $300^{\circ} \mathrm{C}$ for which two isotherm times were tested, at 30 and 60 minutes, in order to find the most efficient one. For the 60 minutes dechlorination step a significant drop of chlorine in the liquids was found.
\end{abstract}

Keywords: electric and electronic equipment, WEEE, WEEE plastic-rich fractions, pyrolysis, stepwise, dechlorination, recycling, circular economy.

\section{INTRODUCTION}

The actual consumption system based on the concept of linear economy, where a given product has a start and an end during its live, has led to actual situation, where scarcity of resources is happening. Resources, as actually known, are not infinite and a great part of them is being dumped as the products are disposed in landfills at the end of their lives with no other previous treatment. In Europe in 2018, 46 wt. \% of the generated waste was disposed, being that the mean value for EU-27, in countries like Bulgaria and Romania that rate is near to 98 wt. \% [1]. These so called wastes, under proper specific treatments, have the possibility of becoming resources that could be used for the manufacturing of the original product or as feed in any other production processes.

The circular economy approach aims for a production system where the generation of wastes is minimised and the value of the products, materials and resources is maintained in the economy as long as possible [2]. The particular case of plastic materials is worth to be analysed in detail, due to, given their versatility, as they are capable of producing a wide range of useful products from wastes.

Among plastics, Waste Electric and Electronic Equipment (WEEE) is an increasing problem in the last years, as worldwide the production is not able to match the collection 
once it has reached the end of its useful live. In Europe, where the awareness for recycling is considered to be well spread among the population, only $5.1 \mathrm{Mt}$ of the $12 \mathrm{Mt}$ generated in the year 2019 were properly collected to be treated [3]. With an average composition consisting of $40 \mathrm{wt}$. \% metals, $30 \mathrm{wt}$. \% plastics and $30 \mathrm{wt}$. \% refractory oxides [4], WEEE is a promising stream from which valuable materials are possible to be obtained. Metallic fraction can be easily recovered from eddy currents and magnetic processes that separate steel, aluminium and cooper from the mix. Critical raw materials as cobalt, antimony, tungsten, gallium, germanium; and near-critical elements such as tin, chromium, lithium, and silver [5] can also be recovered from already well-known pyro/hydrometallurgical treatments [6].

On the other hand, the remaining plastic rich fraction, after the metallic separation, is considered as a waste stream and is mostly headed to landfills or used, in a lower extent, as fuel in cement kilns. The complexity of this polymer mix in the fraction is on average: PP 3 wt. \%, PBT 3 wt. \%, PVC 4 wt. \%, styrene-based polymers (principally ABS) 50 wt. \% and thermosetting resins (epoxy/phenolic resins) $24 \mathrm{wt}$. \% [7]. It is not possible to treat this mix by mechanical recycling processes, as the incompatibility between some of the polymers would deteriorate the final product, making it not suitable for putting on market. There are different options for the recycling of plastics. Thermochemical recycling methods, based on the decomposition of the polymers under the action of heat and with a regulated atmosphere, bring an opportunity for the conversion of the wastes to a wide range of useful products.

Pyrolysis is one of the best known and most used thermochemical processes in these days, working on relatively low temperatures, in a range of $300^{\circ} \mathrm{C}$ to $700^{\circ} \mathrm{C}$, and with an inert atmosphere is capable of decomposing the feed, via cracking mechanisms, into three different fractions: solid one, can be used as fuel, adsorbent, soil amender metallurgical redactor; the liquid fraction which can be used as fuel or chemical precursor, and a gas fraction that is normally used as fuel. In addition, this technology allows to operate on large and small scale plants, being possible the creation of mobile plants which would facilitate the treatment of the wastes. Several studies have been already proven successful in pyrolysis for plastic recycling [8].

In the recycling of WEEE, it has been tested by different researchers the presence of halogenated organic compounds in the mix, having their origin in the polymer/plastic structure. As an example, PVC (contributes with a $56.7 \mathrm{wt} \%$ of chlorine) has a considerable presence in the mix due to its role as wire insulator. For other plastics, brominated flame retardants (BFR) are used as additives in order to prevent the devices of catching fire due to an unexpected malfunction. The halogens in presence of organic matter can lead to the formation of polychlorinated dibenzo-p-dioxin/furans (PCDD/Fs), among several others, which can be formed during crude thermal processes of WEEE recycling, being released to the atmosphere or being held in the pyrolysis products. The PCDD/Fs can infiltrate the food chain or/and have a direct impact in human health [9].

Trying to mitigate the presence of pollutants in the pyrolysis products, at least on those that will be used as fuels, different approaches have been made. Catalytic pyrolysis has been used to break the bonds of halogen-organic compounds in order to free the vapours of halogens once the bonds are already formed. This method also allows the in-situ upgrading of the vapours, improving the quality or the quantity of a targeted element. Another approach, without the need of any catalyst or adsorbent, and for instance more economic, is the stepwise pyrolysis. This process consist on a thermal degradation step that happens around $300^{\circ} \mathrm{C}$ to break the $\mathrm{C}-\mathrm{Cl}$ bond and releases chlorine while no other substances are released. Once the pollutant has been released, the temperature can be increased to normal working standards for the generation of valuable non-harm products. 
The aim of this work is to valorise a rejected plastic-rich stream from WEEE recycling plants through pyrolysis, in order to produce a liquid fraction with potential to be used as an alternative fuel or as a secondary raw material for refineries. Special attention has been put to the halogen content in the pyrolysis products and a step wise pyrolysis process has been held to reduce the chlorine content in the liquid product. The results obtained in the pyrolysis of the plastic-rich stream rejected on a WEEE recycling plant are be presented. For that purpose, characteristics of the liquids, composition and HHV, and chlorine and bromine content are measured.

\section{MATERIALS AND METHODS}

\subsection{Preparation of the sample}

The WEEE sample pyrolyzed was provided by a Spanish company devoted to the integrated management of such type of waste. It consisted in a rejected stream obtained in a WEEE recycling plant once the metallic fraction has been isolated and collected, which is usually landfilled or used as fuel in cement kilns. The sample received was dried for 72 hours under room conditions until equilibrium moisture was achieved, and then quartered, in order to obtain homogenous and representative samples. Finally, the sample was sieved to a particle size in the range 4-12 $\mathrm{mm}$ for the pyrolysis experiments; in addition, a small amount of these quartered samples was further milled into a smaller particle size $(<2 \mathrm{~mm})$, for its characterization purpose. Fig. 1 shows a picture of such sample.

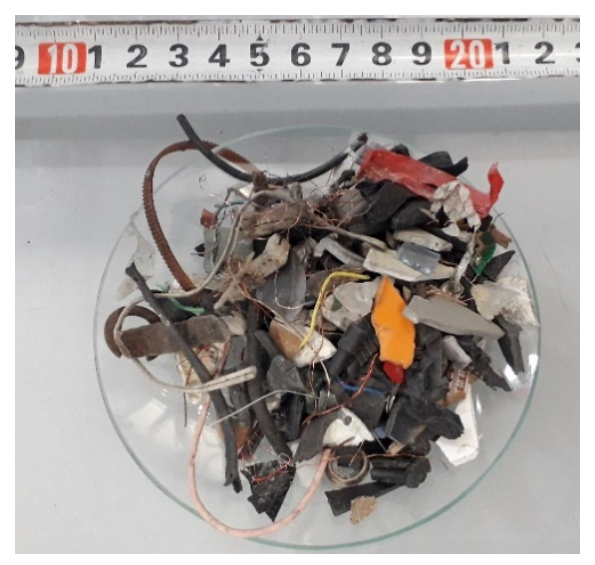

Figure 1: Sample dry and quartered.

\subsection{Pyrolysis experiments}

The pyrolysis experiments were carried out in a laboratory scale plant shown in Fig. 2. The plant is composed by a non-stirred $3.5 \mathrm{dm}^{3}$ stainless steel tank reactor working in a semibatch operation at atmospheric pressure, where the pyrolysis process takes place, and a vapours condensation and gas liquid separation section, where the liquids are collected. The remaining gas fraction flows through an activated carbon column for filtration and is then finally collected in $25 \mathrm{~L}$ Tedlar plastic bags for gas chromatographic analysis. The char formed remains in the reactor and is collected once it is cool down. All the experiments were 
performed with a feeding of $100 \mathrm{~g}$ of sample, $15^{\circ} \mathrm{C} / \mathrm{min}$ heating rate, and additionally, $1 \mathrm{dm}^{3} / \mathrm{min}$ of $\mathrm{N} 2$ all through the run, in order to maintain the inert atmosphere and sweep the pyrolysis vapours from the reactor. Thus, three different pyrolysis experiments were studied: (1) conventional pyrolysis, in which the system was heated to $500^{\circ} \mathrm{C}$, and maintained there for $30 \mathrm{~min}$; (2) stepwise pyrolysis 1 hour, in which a first dechlorination step was carried out at $300^{\circ} \mathrm{C}$ during 60 minutes and then the temperature was raised at $15^{\circ} \mathrm{C} \mathrm{min}^{-1}$ to $500^{\circ} \mathrm{C}$ to complete the pyrolysis process and held for 30 minutes; and (3) stepwise pyrolysis 0.5 hour, where the first dechlorination step was performed in the same conditions that (2) but was held for 0.5 hours and then heated to $500^{\circ} \mathrm{C}$ as in the cracking steps of (1) and (2). These operation conditions were selected based on previous experiments carried out by the authors in similar research with other polymer waste [10]. Besides, the dechlorination step temperature was chosen according to the thermogravimetric analysis of the sample previously obtained.

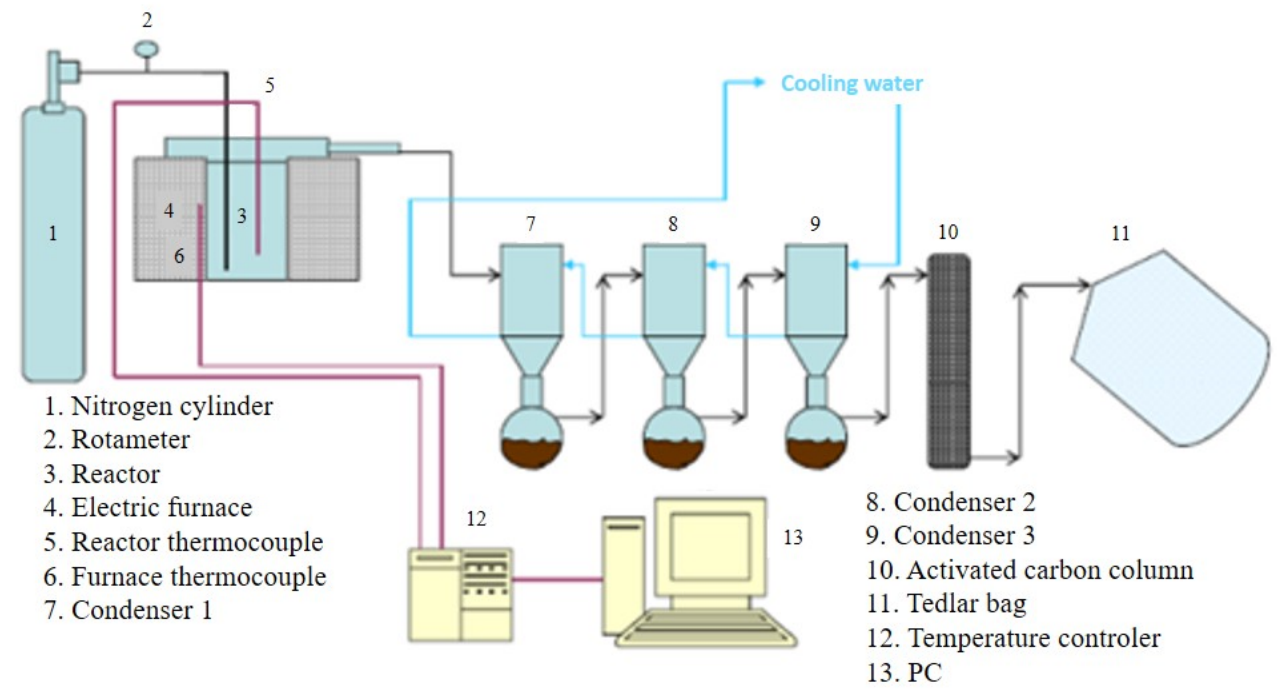

Figure 2: Pyrolysis plant.

\subsection{Analytical techniques}

Visual inspection, infrared spectroscopy (FTIR and NIR) and flame analysis were performed to determine the composition of the WEE sample. Thermogravimetric behaviour was studied in a Mettler Toledo TGA/SDTA851 thermobalance by means of dynamic analysis from 30 to $900^{\circ} \mathrm{C}$ under a $10^{\circ} \mathrm{C} / \mathrm{min}$ heating rate in a $50 \mathrm{~cm}^{3} / \mathrm{min}$ nitrogen inert atmosphere. Proximate analysis was performed in a LECO TGA-701 thermobalance, following the ASTM D7582 standard. Ultimate analysis was carried out in a LECO TruSpec CHNS automatic analyser, which complies the ASTM D5373 standard. The determination of the higher heating value (HHV) was conducted in a LECO AC-500 automatic calorimeter, according to the ASTM D3286 standard.

With respect to the pyrolysis gases, they were identified and quantified by an Agilent 7890 gas chromatograph (GC), equipped with a thermal conductivity and a flame ionization detector (TCD and FID, respectively). The composition of pyrolysis liquids was also 
measured by gas chromatography (GC), Agilent 6890, coupled to a mass spectroscopy detector Agilent 5973 (MS). The identification was carried out comparing the spectrum retention time with a commercial library of mass spectra and MS literature data.

The chlorine content was quantified by following the UNE-EN 1548:2011 standard, which consists in the combustion of the sample in a calorimetric bomb and the absorbing of chlorinated gaseous substances in a $0.25 \mathrm{M} \mathrm{NaOH}$ solution. The gases produced flow out of the combustion vessel to be held in a $10 \mathrm{~L}$ Tedlar plastic bag. Additionally a pump is used to force the gases flow through a bubbler with the basic solution and the remaining gases are kept in a different Tedlar plastic bag to be later released, as it can be seen in Fig. 3. Then, the solution is analysed by ionic chromatography (Dionex ICS 3000). Bromine content was determined in the same way.

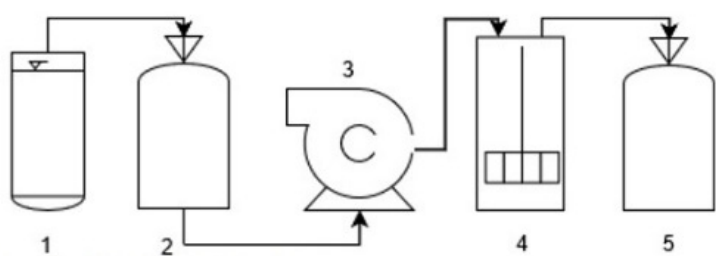

1. Combustion vessel

2. Tedlar $10 \mathrm{~L}$ plastic bag

3. Pump

4. Bubbler

5. Tedlar $10 \mathrm{~L}$ plastic bag

Figure 3: Halogens recovery system.

\section{RESULTS AND DISCUSSION}

\subsection{Characterization of the sample}

Tables 1 and 2 show the composition and thermo-chemical properties of the WEEE sample. The predominant styrenic nature of the sample ( $45 \mathrm{wt} . \%)$ and a high plastic content can be seen. The composition analysis matched the proximate analysis, which shows a high content of volatile matter ( $83.2 \mathrm{wt} . \%)$ due to the organic nature of this type of waste. The acceptable $\mathrm{HHV}\left(30 \mathrm{MJ} \mathrm{kg}^{-1}\right)$ is justified by the high content of carbon measured in the ultimate analysis (74 wt. \%).

The thermogravimetric behaviour of the sample is presented in Fig. 4. It shows two main degradation steps, due to the bond breaking mechanisms at two different temperatures. The first one, from $250^{\circ} \mathrm{C}$ to $350^{\circ} \mathrm{C}$, corresponds to the chlorine release by the break of $\mathrm{C}-\mathrm{Cl}$ bonds, fact that is in agreement with other works [11]. The second degradation step, from $350^{\circ} \mathrm{C}$ to $510^{\circ} \mathrm{C}$, is attributed to the cracking of the plastics where $\mathrm{C}-\mathrm{C}$ and $\mathrm{C}-\mathrm{H}$ bonds are broken to produce mainly the original monomers of the polymers and new hydrocarbons.

\subsection{Pyrolysis yields and characterization of pyrolysis liquids}

The obtained pyrolysis yields, in case of conventional pyrolysis, and with stepwises of $1 \mathrm{~h}$ and $0.5 \mathrm{~h}$ are presented in Table 3. The data presented include the mean value and the standard deviation of at least two equivalent experiments that did not differ one another more than four points in wt. \%. 
Table 1: Sample composition (wt. \%).

\begin{tabular}{|l|c|}
\hline \multicolumn{2}{|c|}{ Material (wt. \%) } \\
\hline Polyolefines & 13.2 \\
\hline Styrenic plastics & 45.0 \\
\hline PVC & 1.7 \\
\hline PVC with metal & 2.0 \\
\hline Other thermoplastics & 23.2 \\
\hline Rubbers & 1.6 \\
\hline Foams & 0.1 \\
\hline Printed circuits & 2.7 \\
\hline Textile & 0.3 \\
\hline Paper/cardboard & 0.1 \\
\hline Magnetic metals & 0.0 \\
\hline Non-magnetic metals & 3.2 \\
\hline Stones & 0.1 \\
\hline Multi-material & 1.5 \\
\hline Others & 5.4 \\
\hline
\end{tabular}

Table 2: Sample thermochemical and HHV analysis.

\begin{tabular}{|c|c|}
\hline \multicolumn{2}{|c|}{ Thermochemical and HHV analysis } \\
\hline \multicolumn{2}{|c|}{$\begin{array}{c}\text { Proximate analysis } \\
\text { (wt. \%, equilibrium humidity) }\end{array}$} \\
\hline Moisture & $0.4 \pm 0.1$ \\
\hline Volatile matter & $83.2 \pm 1.5$ \\
\hline Fixed carbon $^{1}$ & $4.5 \pm 0.4$ \\
\hline Ashes & $11.9 \pm 1.4$ \\
\hline \multicolumn{2}{|c|}{$\begin{array}{c}\text { Ultimate analysis } \\
\text { (wt. \%, dry and ash free basis) }\end{array}$} \\
\hline $\mathrm{C}$ & $74.5 \pm 2.4$ \\
\hline $\mathrm{H}$ & $7.7 \pm 0.3$ \\
\hline $\mathrm{N}$ & $2.2 \pm 0.2$ \\
\hline $\mathrm{S}$ & $0.2 \pm 0.1$ \\
\hline $\mathrm{Br}$ & $0.6 \pm 0.1$ \\
\hline $\mathrm{O}$ & $9.1 \pm 2.6$ \\
\hline Others $^{1}$ & $5.7 \pm 2.6$ \\
\hline \multicolumn{2}{|c|}{ Heating value ( $\mathrm{MJ} \mathrm{kg}^{-1}$, dry basis) } \\
\hline HHV & $30.2 \pm 0.2$ \\
\hline LHV & $28.7 \pm 0.2$ \\
\hline Useful LHV & $28.5 \pm 0.2$ \\
\hline
\end{tabular}

${ }^{1}$ by difference. 


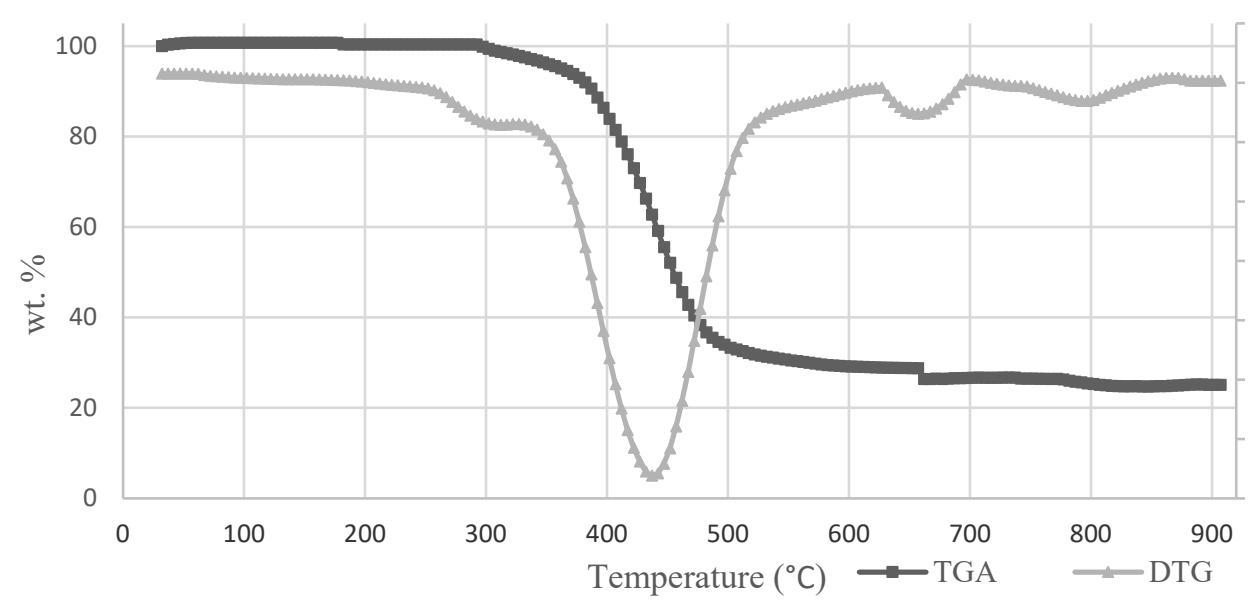

Figure 4: WEEE thermogravimetric behaviour.

Table 3: Pyrolysis yields (wt. \%).

\begin{tabular}{|l|c|c|c|}
\hline \multicolumn{4}{|c|}{ Pyrolysis yields (wt. \%) } \\
\hline & Conventional & Stepwise 1 h & Stepwise 0.5 h \\
\hline Liquids & $69.9 \pm 0.8$ & $70.2 \pm 1.4$ & $68.7 \pm 2.4$ \\
\hline Gases ${ }^{1}$ & $9.4 \pm 1.5$ & $8.3 \pm 0.1$ & $11.8 \pm 4.5$ \\
\hline Char & $20.8 \pm 1.6$ & $21.5 \pm 1.4$ & $19.4 \pm 2.0$ \\
\hline
\end{tabular}

${ }^{1}$ by difference.

It can be seen that the liquid products are the main fraction in all the pyrolysis tests, ranging around $70 \mathrm{wt} . \%$ in the three type of experiments. The solid fraction yields are about $20 \mathrm{wt} . \%$, and are similar in the different experiments. As the gas yields are calculated by difference, it matched for all cases, not being greater than the $15 \mathrm{wt} . \%$ in any test.

So, it can be concluded that the dechlorination and cracking steps have no effect on the pyrolysis products distribution.

The composition of the obtained pyrolysis liquids in the three type of experiments determined by GC/MS are shown in Table 4. Under "Not identified" all the compounds with a match quality provided by the MS search engine lower than $85 \%$ have been included. Additionally, the HHV of the liquids produced are included in Table 4. It can be seen that the liquids from the three type of experiments present a typical composition of a pyrolysis liquid coming from a styrenic-rich plastic stream, with a high content of styrene, ethyl-benzene and toluene. Phenol and its derivatives are also notable, which could be related to the presence of oxygen in the sample. Finally, the presence of benzenebutanenitrile is probably due to the nitrile groups in the polymers of the sample.

If the data obtained in the conventional pyrolysis and stepwise dechlorination pyrolysis are compared, it can be observed that the content of the main components (styrene, ethylbenzene and toluene) is higher in the conventional pyrolysis experiments (41.6, 13.2 and $7.7 \%$ area, respectively). If the dechlorination step is carried out, these components are higher 
Table 4: GC/MS composition of pyrolysis liquids (\% area) and HHV.

\begin{tabular}{|l|c|c|c|}
\hline \multicolumn{4}{|c|}{ Liquids composition (area \%) } \\
\hline & $\begin{array}{c}\text { Conventional } \\
\text { pyrolysis }\end{array}$ & 0.5 h stepwise & 1 h stepwise \\
\hline Styrene & $41.6 \pm 2.5$ & $34.3 \pm 2.8$ & $31.8 \pm 0.7$ \\
\hline Etilbenzene & $13.2 \pm 1.1$ & $10.3 \pm 0.9$ & $9.4 \pm 0.1$ \\
\hline Toluene & $7.7 \pm 0.5$ & $6.1 \pm 0.7$ & $4.4 \pm 0.4$ \\
\hline$\alpha$-metilestirene & $6.9 \pm 0.2$ & $5.2 \pm 1.1$ & $6.3 \pm 1.1$ \\
\hline Phenol & $10.4 \pm 1.3$ & $10.0 \pm 0.1$ & $10.8 \pm 0.5$ \\
\hline Alkylphenol & $6.6 \pm 1.5$ & $7.1 \pm 1.0$ & $7.9 \pm 0.6$ \\
\hline Benzenebutaneni-trile & $3.5 \pm 0.2$ & $4.4 \pm 0.2$ & $5.2 \pm 0.4$ \\
\hline Benzene derivatives & n.d. ${ }^{1}$ & $7.2 \pm 0.6$ & $12.2 \pm 0.45$ \\
\hline Not identified & $7.6 \pm 1.4$ & $11.0 \pm 1.2$ & $12.4 \pm 0.8$ \\
\hline HHV (MJ kg ${ }^{-1}$ ) & $36.2 \pm 1.8$ & $36.1 \pm 0.6$ & $35.8 \pm 0.6$ \\
\hline
\end{tabular}

for the shorter treatment $(34.3 \%, 10.3 \%$ and $6.1 \%$ area versus $31.8 \%, 9.4 \%$ and $4.4 \%$ area, respectively). On the contrary, the presence of other benzene derivatives grows as the dechlorination step time increases.

The liquids composition was confirmed by the ultimate organic analysis which revealed a carbon plus hydrogen content of $86 \%$ of the total weight, as shown in Table 5 .

With respect to the HHV, are slightly lower than the common values of traditional fossil fuels, as natural gas $(52.2 \mathrm{MJ} / \mathrm{kg})$, in all the experiments, but would be acceptable in order to be used as alternative fuels.

Table 5: Pyrolysis liquid ultimate analysis (wt. \%).

\begin{tabular}{|l|c|}
\hline \multicolumn{2}{|c|}{ Liquids ultimate organic analysis (wt. \% ) } \\
\hline & Conventional pyrolysis \\
\hline $\mathrm{C}$ & $78.4 \pm 8.5$ \\
\hline $\mathrm{H}$ & $7.8 \pm 0.1$ \\
\hline $\mathrm{N}$ & $2.0 \pm 0.3$ \\
\hline $\mathrm{S}$ & $0.1 \pm 0.0$ \\
\hline Others $^{1}$ & $11.2 \pm 8.5$ \\
\hline
\end{tabular}

${ }^{1}$ by difference.

\subsection{Chlorine content in the sample and products}

According to the results shown in the Table 6, the chlorine content in the raw WEEE sample is $7,767 \mathrm{ppm}$, which corresponds to a total of $0.78 \mathrm{~g}$ from the $100 \mathrm{~g}$ pyrolysed sample. After the conventional pyrolysis treatment, this pollutant is distributed between the three fractions generated (solid, liquid, gas). Hus, the concentration on the solid is about 11,531 ppm, which means, taking into account the yields, that $0.23 \mathrm{~g}$ of the chlorine have not be released during the process. For the liquids, the concentration is lower, 5,375 ppm. But given the high liquid yield, liquid is the principal receptor of the chlorine with near $0.38 \mathrm{~g}$ of the initial content. Chlorine concentration on gases from conventional pyrolysis is calculated by difference, 
Table 6: Chlorine concentration in the sample and products.

\begin{tabular}{|l|c|}
\hline \multicolumn{2}{|c|}{ Chlorine content (ppm) } \\
\hline Raw sample & $7,767.8 \pm 770.3$ \\
\hline Conventional pyrolysis solid & $11,531.5 \pm 2,777.2$ \\
\hline Conventional pyrolysis liquid & $5,375.1 \pm 2,247.1$ \\
\hline 0.5 h stepwise pyrolysis liquid & $4,251.5 \pm 2,280.8$ \\
\hline 1 h stepwise pyrolysis liquid & $3,283.0 \pm 764.9$ \\
\hline Conventional pyrolysis gas $^{1}$ & 17,000 \\
\hline
\end{tabular}

${ }^{1}$ by difference

supposing that the rest of the chlorine is released into gas form. Stepwise pyrolysis shows a reduction in the chlorine content in the liquids, reaching a maximum in the 1 hour dechlorination step.

\section{CONCLUSIONS}

The aim of this work was the production of a liquid fuel from WEEE pyrolysis process: so, it is the fraction that has to be maximized. In view of the results presented, it can be concluded that, in fact, the WEEE sample studied seems to be appropriate to produce an alternative fuel, for the following reasons: (1) a great amount of liquids, around $70 \mathrm{wt} . \%$ are produced; (2) the obtained liquids have a low quantity of sulphur, which is decisive for their application; and (3) the quantity of aromatic compounds of interest is relevant $(\approx 70 \%$ area).

The pyrolysis isothermal stage at $300^{\circ} \mathrm{C}$ does not change the composition nor the yield of the liquids generated and offers very similar results than in the conventional pyrolysis. The chlorine content in the liquids obtained, which in the best test was reduced to $3,283 \mathrm{ppm}$, means a significant reduction compared with the $7,767 \mathrm{ppm}$ present in the original sample. Considering the maximum chlorine concentration in fuels should be less than $100 \mathrm{ppm}$, further dechlorination processes, apart from the stepwise pyrolysis, would be necessary for the use of this sample as commercial fuel.

Being this work focused on the technical feasibility of the process under study, the analysis of the economic feasibility of the production of a liquid fuel from the pyrolysis process of WEEE will be carried out in the near future. However, the efficiency shown by this technique is a promising starting point.

\section{ACKNOWLEDGEMENT}

This research was funded by the Basque Government through the project with reference KK2020/00107 (ELKARTEK program).

\section{REFERENCES}

[1] European Statistics-Eurostat, Energy, transport and environment statistics, 2020 edition. 2020.

[2] European Commission, Report on critical raw materials and the circular economy, 2018.

[3] Forti, V., Baldé, C.P., Kuehr, R. \& Bel, G., The global e-waste monitor 2020, July 2020. 
[4] Salbidegoitia, J.A., Fuentes-Ordóñez, E.G., González-Marcos, M.P., GonzálezVelasco, J.R., Bhaskar, T. \& Kamo, T., Steam gasification of printed circuit board from e-waste: Effect of coexisting nickel to hydrogen production. Fuel Process. Technol., 133, pp. 69-74, 2015. DOI: 10.1016/j.fuproc.2015.01.006.

[5] Iş1ldar, A. et al., Biotechnological strategies for the recovery of valuable and critical raw materials from waste electrical and electronic equipment (WEEE): A review. $J$. Hazard. Mater., 362, pp. 467-481, 2019. DOI: 10.1016/j.jhazmat.2018.08.050.

[6] Kanaujia, K., Trivedi, A., Upvan, K. \& Hait, S., Hybrid Bioleaching: An Emerging Technique for Extraction of Critical Metals from WEEE, Elsevier Inc., 2021.

[7] Esposito, L., Cafiero, L., De Angelis, D., Tuffi, R. \& Vecchio Ciprioti, S., Valorization of the plastic residue from a WEEE treatment plant by pyrolysis. Waste Manag., 112, pp. 1-10, 2020. DOI: 10.1016/j.wasman.2020.05.022.

[8] Dogu, O. et al., The chemistry of chemical recycling of solid plastic waste via pyrolysis and gasification: State-of-the-art, challenges, and future directions. Prog. Energy Combust. Sci., 84, 100901, 2021. DOI: 10.1016/j.pecs.2020.100901.

[9] Kiddee, P., Naidu, R. \& Wong, M.H., Electronic waste management approaches: An overview. Waste Manag., 33(5), pp. 1237-1250, 2013. DOI: 10.1016/j.wasman.2013.01.006.

[10] López, A., De Marco, I., Caballero, B.M., Laresgoiti, M.F. \& Adrados, A., Influence of time and temperature on pyrolysis of plastic wastes in a semi-batch reactor. Chem. Eng. J., 173(1), pp. 62-71, 2011. DOI: 10.1016/j.cej.2011.07.037.

[11] López, A., De Marco, I., Caballero, B.M., Laresgoiti, M.F. \& Adrados, A., Dechlorination of fuels in pyrolysis of PVC containing plastic wastes. Fuel Process. Technol., 92(2), pp. 253-260, 2011. DOI: 10.1016/j.fuproc.2010.05.008. 